\title{
Benign Blockage: Gastric Outlet Obstruction due to a Prolapsing Gastric Pedunculated Polyp-Case Report and Literature Review
}

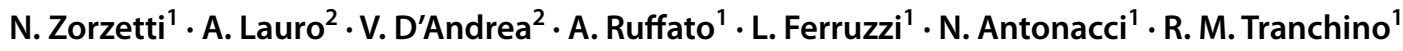

Accepted: 28 January 2021

(c) The Author(s), under exclusive licence to Springer Science+Business Media, LLC part of Springer Nature 2021

Keywords Pedunculated gastric polyps $\cdot$ Prolapse $\cdot$ Duodenal bulb $\cdot$ Bowel obstruction $\cdot$ Valve effect

$\begin{array}{ll}\text { Abbreviations } \\ \text { WBC } & \text { White blood cells } \\ \text { Hgb } & \text { Hemoglobin } \\ \text { CRP } & \text { C-reactive protein } \\ \text { PPIs } & \text { Proton pump inhibitor } \\ \text { EUS } & \text { Endoscopic ultrasonography } \\ \text { HFUPS } & \text { High-frequency ultrasound probe sonography } \\ \text { ESD } & \text { Endoscopic submucosal dissection } \\ \text { MI } & \text { Myocardial infarction } \\ \text { NPO } & \text { Nihil per os } \\ \text { IV } & \text { Intravenous } \\ \text { EGD } & \text { Esophago-gastro-duodenoscopy }\end{array}$

\section{Case Report and Evolution}

An 89-year-old woman was admitted to the emergency department at "Ospedale Civile Umberto I" in Lugo (Ravenna) for 1 month of vomiting, mild epigastric pain, and postprandial diarrhea without fever. Main comorbidities included chronic atrial fibrillation treated with a direct-acting oral anticoagulant, previous MI, hypertension, diabetes, and hypercholesterolemia, though despite her age the patient was autonomous in her daily activities. On admission, laboratory tests included normal WBC count, $\mathrm{Hgb}$, and CRP. Abdominal X-ray demonstrated a stomach filled by ingested food (Fig. 1a) and diffuse air-fluid levels accompanied by

A profile of Noemi Zorzetti is available at https://doi.org/10.1007/ s10620-021-06891-w.

N. Zorzetti

noemi.zorzetti@gmail.com

1 Department of General Surgery, “Ospedale Civile Umberto I", Lugo, Ravenna, Italy

2 Department of Surgical Sciences, La Sapienza University, Rome, Italy abdominal distension (Fig. 1b). A surgical consultation was requested; a CT scan was performed confirming gastric distension by ingested food (Fig. 2).

Since gastric outlet obstruction was suspected, the patient was hospitalized in a medical unit, treated with NPO and IV fluids. After 2 weeks, a second surgical consultation was requested due to the recurrence of clinical symptoms with unchanged laboratory tests. An upper GI series reported normal gastric and duodenal transit (Fig. 3) while colonoscopy was negative. The patient underwent EGD that showed a 4-cm pedunculated polyp situated in the gastric antrum; the polyp prolapsed into the duodenal bulb creating a "ball valve"-type intermittent obstruction. Biopsy was consistent with a hyperplastic polyp which was endoscopically resected (Fig. 4a-c). The final histological report confirmed a benign lesion; the patient was discharged from the hospital without any further invasive treatment in good general condition.

\section{Discussion}

Gastric polyps are either sessile or pedunculated lesions originating in the gastric epithelium or submucosa and protruding into the lumen. Though polyps are usually asymptomatic, the widespread use of endoscopy has increased the detection of incidental lesions [1,2] even in childhood [3]. Larger polyps can manifest with bleeding, iron deficiency anemia, abdominal pain, or gastric outlet obstruction. Since these lesions can have a malignant potential, all gastric polyps detected at endoscopy should be biopsied [4]. The WHO classification of gastric polyps remains controversial [5, 6].

Among benign gastric polyps, the most common include fundic gland polyps that can be sporadic [7-12], associated with the long-term use of PPIs [12-16] or related to familial syndromes [17]; hyperplastic polyps that constitute $>90 \%$ of benign gastric polyps [18]; and adenomas that are true neoplasms and precursors of gastric cancer [19, 20]. Gastric 
Fig. 1 a Abdominal X-ray at admission showing stomach filled by ingested food (red arrow). b Abdominal X-ray at admission showing diffuse air-fluid levels (red arrow) with abdominal distension (a)

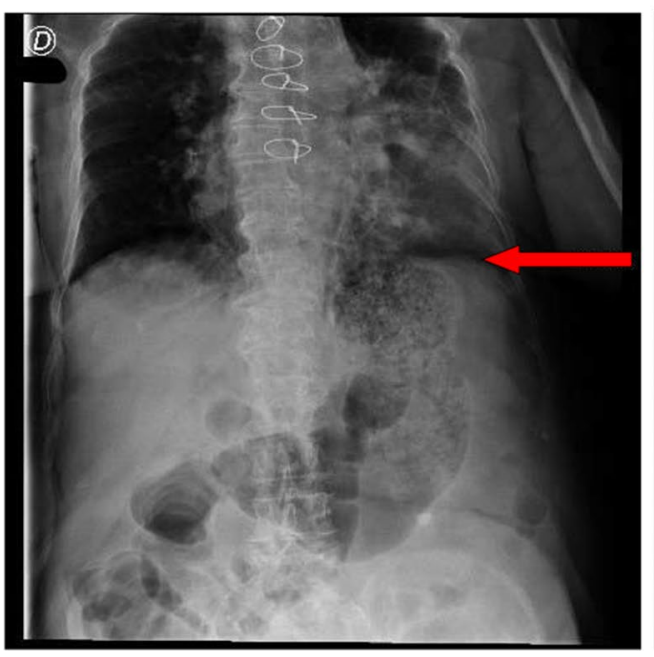

(b)

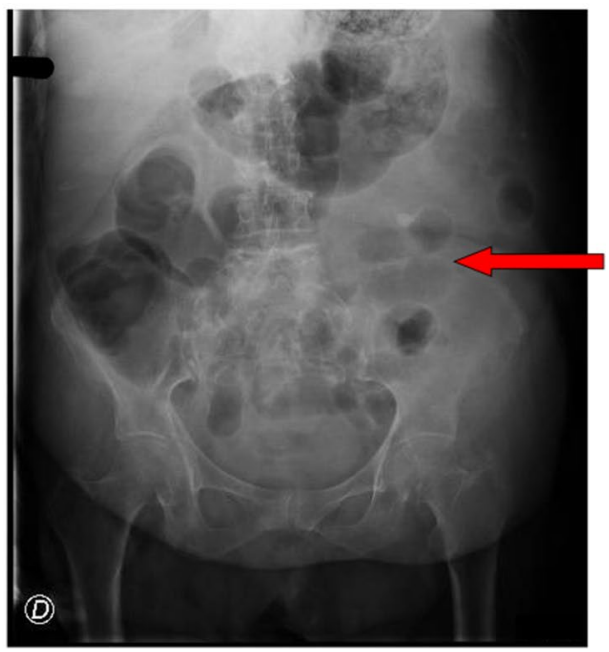

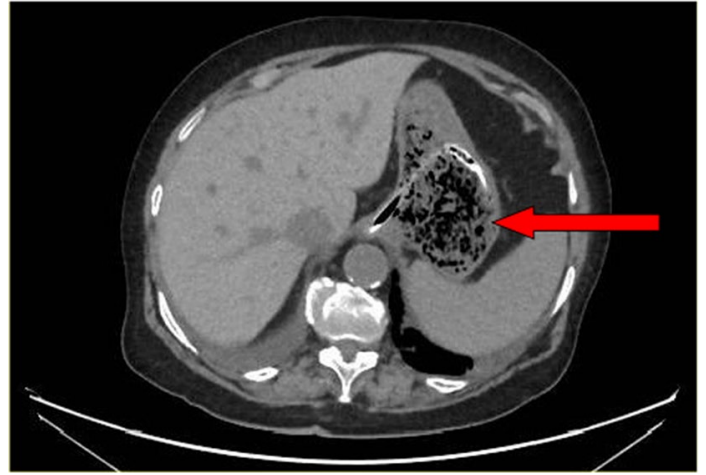

Fig. 2 Abdominal CT scan at admission confirming gastric distension due to ingested food (red arrow)

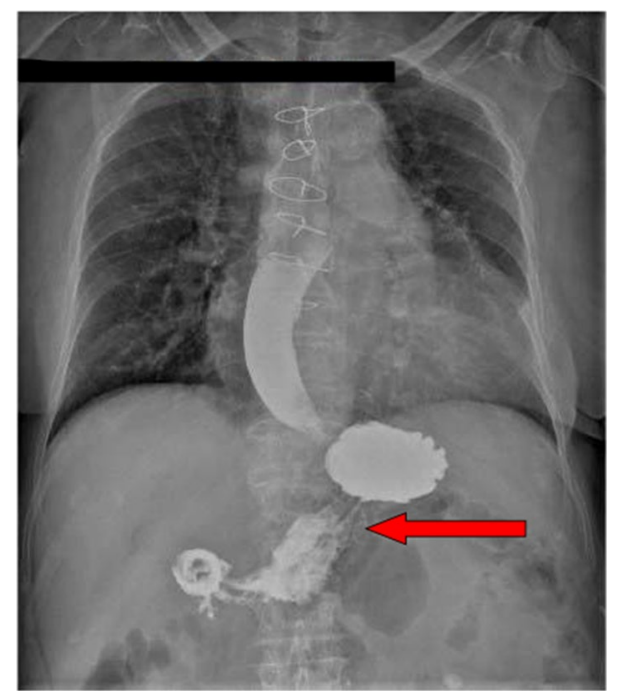

Fig. 3 Upper GI series showing normal gastric and duodenal transit (red arrow) polyps can occur in precancerous conditions such as chronic atrophic gastritis, dysplasia, or intestinal metaplasia. EUS and HFUPS can accurately determine the depth of invasion in case of early gastric cancer [21], whereas ESD can often substitute for more aggressive surgical procedures [22].

A literature review identified other case reports describing "ball valve" gastric outlet obstruction due to gastric polyps of diverse histological types [Table 1]. Suzuki et al. found a large $(3.5 \mathrm{~cm})$ pedunculated polyp-shaped gastric cancer prolapsing into the duodenal bulb [22], whereas Miyake and coll described a $6-\mathrm{cm}$ pedunculated polyp that intermittently obstructed the gastric outlet [23], both treated by ESD. Sone et al. reported a large pedunculated polyp prolapsing through the pylorus into the duodenal bulb, with the stalk arising from the greater curvature and extending beyond the angularis; thanks to air insufflation, the patient belched and the polyp suddenly fell back into the stomach [24]. Sooklal and coll identified a large polyp arising from the gastric cardia with a thick stalk and a bulky shape that had prolapsed into the duodenum [25].

Progressive gastric outlet obstruction is the most common symptom [26-32] even if, in some cases, it can be intermittent with vomiting and recurrent epigastric pain, often eluding ready diagnosis [33-40]. Rarely, polyps protrude distally, obstructing the ampulla of Vater, with subsequent dilatation of the common bile and main pancreatic ducts, another rare presentation that can include acute pancreatitis and biliary obstruction [41, 42].

In conclusion, gastric polyps are often asymptomatic and found incidentally at upper endoscopy performed for unrelated reasons. Although they are considered benign lesions, all symptomatic polyps should be removed in order to confirm histological diagnosis while resolving symptoms and preventing potential malignant transformation. In fact, simple gastric hyperplastic polyps and those with neoplastic 
(a)

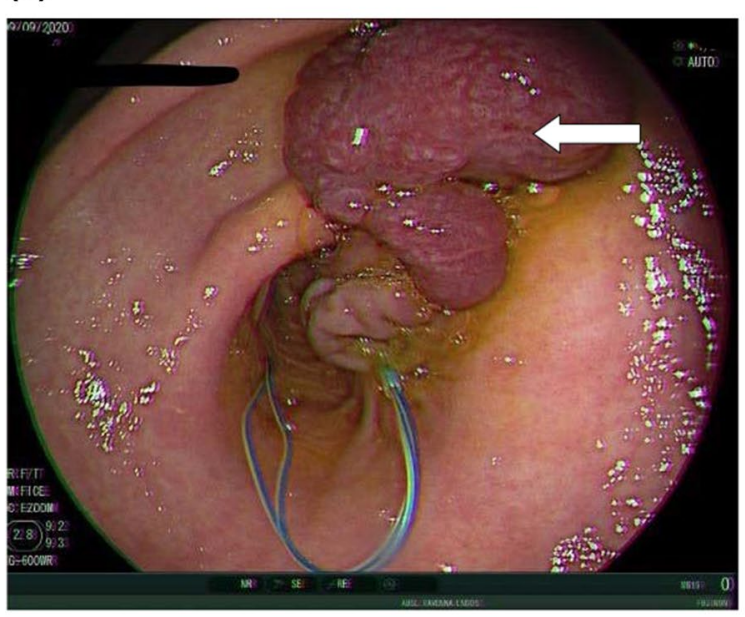

(b)

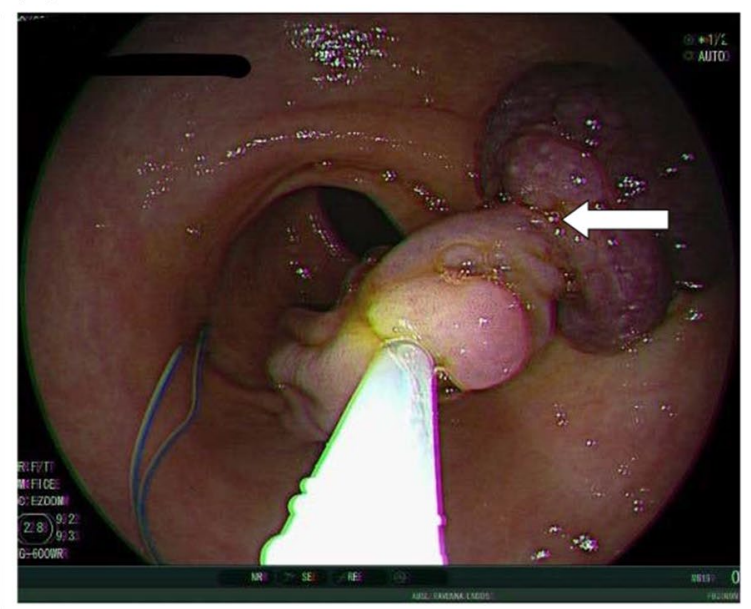

(c)

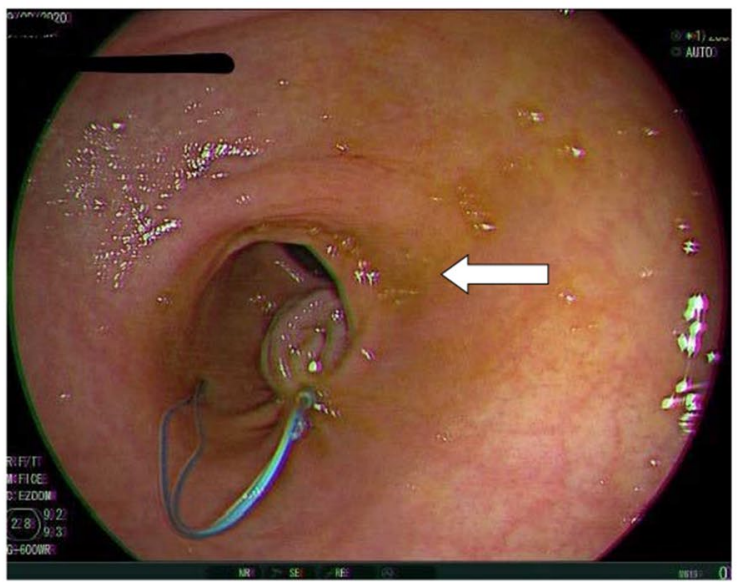

Fig. 4 a Upper gastrointestinal endoscopy showing a pedunculated polyp (white arrow). b Endoscopic resection of pedunculated gastric polyp (white arrow). c Final view of the endoscopic procedure-white arrow indicates the area of previous resection

transformation are indistinguishable in terms of number, location, and gross appearance [34].

In this case, gastric outlet obstruction was due to a 4-cm hyperplastic lesion, although most prolapsing polyps are $<2 \mathrm{~cm}$ in diameter [7-9, 18]. Endoscopic resection with subsequent clinical observation relieved the symptoms and confirmed the diagnosis.

\section{Key Messages}

- Though gastric polyps are usually asymptomatic, they can have malignant potential. Therefore, all types of gastric polyps detected at endoscopy need to be biopsied or removed.

- Larger polyps can manifest with bleeding, anemia, abdominal pain, or gastric outlet obstruction.

- Though "ball valve" obstruction due to a polyp originating in the gastric antrum is not a common cause of gastric outlet obstruction, this etiology must be considered once the most frequent causes have been excluded.

- Appropriate management of gastric polyps depends on their histology, symptomatology, malignant potential, and comorbidities. 
Table 1 Gastric polyps causing intermittent gastric outlet obstruction by a "ball valve" mechanism (n.a. =not available)

\begin{tabular}{|c|c|c|c|}
\hline Literature (ref) & Polyp dimension & Histology & Treatment \\
\hline Suzuki et al. [22] & $3.5 \mathrm{~cm}$ & Early gastric cancer $\mathrm{pT} 1 \mathrm{a}$ & ESD \\
\hline Miyake et al. [23] & $6 \mathrm{~cm}$ & Well-differentiated adenocarcinoma & ESD \\
\hline Sone et al. [24] & $3.8 \times 3.6 \times 2.1 \mathrm{~cm}$ & Hyperplastic polyp & Snare polypectomy \\
\hline Sooklal et al. [25] & $10 \mathrm{~cm}$ & Adenoma with low grade of dysplasia & ESD with the clip-snare method \\
\hline Cerwenka et al. [26] & n.a & Hyperplastic polyp & Snare polypectomy \\
\hline Yriberry Urena et al. [27] & n.a & Hyperplastic polyp & $\begin{array}{l}\text { Endoscopic resection and argon plasma } \\
\text { coagulation }\end{array}$ \\
\hline Chen et al. [28] & $6 \mathrm{~cm}$ & Hyperplastic polyp & Total removal \\
\hline Dean et al. [29] & $10 \times 7 \times 4.5 \mathrm{~cm}$ & Hyperplastic polyp & Laparotomic surgical resection \\
\hline Aydin et al. [30] & $2.5 \mathrm{~cm}$ & Hyperplastic polyp & Snare polypectomy \\
\hline Burus et al. [31] & $4 \mathrm{~cm}$ & $\begin{array}{l}\text { Hyperplastic polyp with early gastric cancer } \\
\text { foci }\end{array}$ & $\begin{array}{l}\text { Endoscopic polypectomy + endoscopic follow- } \\
\text { up }\end{array}$ \\
\hline Lei et al. [32] & $3 \mathrm{~cm}$ & Hyperplastic polyp & $\begin{array}{l}\text { Endoloop-assisted electrosurgical polypec- } \\
\text { tomy }\end{array}$ \\
\hline \multirow[t]{4}{*}{ Kumar et al. [33] } & I) $8 \mathrm{~cm}$ & I) Adenoma & I) Endoscopic polypectomy \\
\hline & II) $9 \times 8 \mathrm{~cm}$ & II) Leiomyoma & II) Laparotomic surgical resection \\
\hline & III) $2 \mathrm{~cm}$ & III) Hyperplastic polyp & III) Endoscopic polypectomy \\
\hline & IV) $3.5 \mathrm{~cm}$ & IV) Hyperplastic polyp & IV) Endoscopic polypectomy \\
\hline Pontone et al. [34] & n.a & Hyperplastic polyp & $\begin{array}{l}\text { Endoscopic polypectomy with hydroxypropyl- } \\
\text { methylcellulose }\end{array}$ \\
\hline Kosai et al. [35] & $\begin{array}{l}4 \text { cm plus multiple } \\
\text { smaller satellite } \\
\text { polyps }\end{array}$ & Hyperplastic polyp & $\begin{array}{l}\text { Distal gastrectomy with Billroth } 2 \text { reconstruc- } \\
\text { tion }\end{array}$ \\
\hline Parikh et al. [36] & $2 \mathrm{~cm}$ & Hyperplastic polyp & Snare polypectomy \\
\hline Sun et al. [37] & $2.5 \mathrm{~cm}$ & Granulation tissue & Detachable snaring without polypectomy \\
\hline Gencosmanoglu et al. [38] & $3 \mathrm{~cm}$ & Hyperplastic polyp & $\begin{array}{l}\text { Snare polypectomy with submucosal injection } \\
\text { of diluted adrenaline }\end{array}$ \\
\hline Freeman [39] & n.a & Adenoma complicated by adenocarcinoma & Endoscopic excision \\
\hline Gashi et al. [40] & $3 \mathrm{~cm}$ & Hyperplastic polyp & Endoscopic excision \\
\hline De La Cruz et al. [41] & $13 \mathrm{~cm}$ & Hyperplastic polyp & Laparotomic surgical resection \\
\hline Jetha et al. [42] & $8.8 \times 4 \times 3.7 \mathrm{~cm}$ & Adenoma plus foci of high-grade dysplasia & Laparotomic surgical resection \\
\hline
\end{tabular}

\section{Compliance with Ethical Standards}

Conflict of interest All authors declare that they have no conflict of interest.

\section{References}

1. Farooq A, Mandzhieva B, Wert J et al. Hyperplastic gastric polyp causing upper gastrointestinal hemorrhage and acute blood loss anemia. Cureus. 2020;12:e8494

2. Inayat F, Ur Rahman A, Wahab A et al. Gastric inflammatory fibroid polyp: a rare cause of occult upper gastrointestinal bleeding. J Investig Med High Impact Case Rep. 2020;8:2324709620936840

3. Khemani S, Ghulam Qadir H, Malik M et al. A neonate with upper GI bleeding. J Coll Physicians Surg Pak. 2019;26:50-51
4. Goddard AF, Badreldin R, Pritchard DM. The management of gastric polyps. BSG (British Society of Gastroenterology) guidelines on the management of gastric polyps. Gut. 2010;59:1270-1276

5. Jass JR, Sobin LH, Watanabe H. The World Health Organization's histologic classification of gastrointestinal tumours. A commentary on the second edition. Cancer. 1990;66:2162-2167

6. WHO classification of Tumours. Pathology and genetics: tumours of the digestive system. Lyon, France: IARC Press; 2000.

7. Stolte M, Stich T, Eidt $\mathrm{S}$ et al. Frequency, location and age and sex distribution of various types of gastric polyps. Endoscopy. 1994;26:659-665

8. Morais DJ, Yamanaka A, Zeitun JM et al. Gastric polyps: a retrospective analysis of 26,000 digestive endoscopies. Arq Gastroenterol. 2007;44:14-17

9. Borch K, Skarsgard J, Franzen L et al. Benign gastric polyps: morphological and functional origin. Dig Dis Sci. 2003;48:1293

10. Weston BR, Helper DJ, Rex DK. Positive predictive value of endoscopic features deemed typical of gastric fundic gland polyps. J Clin Gastroenterol. 2003;36:399-402

11. Abraham SC, Nobukawa B, Giardiello FM et al. Fundic gland polyps in familial adenomatous polyposis coli gene alteration. Am J Pathol. 2000;157:747-754 
12. Jalving $\mathbf{M}$, Koornstra JJ, Wesseling $\mathbf{J}$ et al. Increased risk of fundic gland polyps during long-term proton pump inhibitor therapy. Aliment Pharmacol Ther. 2006;24:1341-1348

13. Choudhry U, Boyce HW Jr, Coppola D. Proton pump inhibitorassociated gastric polyps: a retrospective analysis of their frequency, and endoscopic, histologic, and ultrastructural characteristics. Am J Clin Pathol. 1998;110:615-621

14. Declich P, Ferrara A, Galati F et al. Do fundic gland polyps develop under long term omeprazole therapy? Am J Gastroenterol. 1998;93:1393

15. Declich P, Ambrosiani A, Bellone $\mathrm{S}$ et al. Fundic gland polyps under omeprazole treatment. Am J Clin Pathol. 1999; 112:576-578

16. Vieth M, Stolte M. Fundic gland polyps are not induced by proton pump inhibitor therapy. Am J Clin Pathol. 2001;116:716-720

17. El-Zimaity HMT, Jackson FW, Graham DY. Fundic gland polyps developing during omeprazole therapy. Am J Gastroenterol. 1997;92:1858-1860

18. Stolte M. Clinical consequences of the endoscopic diagnosis of gastric polyps. Endoscopy. 1995;27:32-37

19. Saito K, Arai K, Mori M et al. Effect of Helicobacter pylori eradication on malignant transformation of gastric adenoma. Gastrointest Endosc. 2000;52:27-32

20. Tomasulo J. Gastric polyps. Histologic types and their relationship to gastric carcinoma. Cancer. 1971;27:1346-1355

21. Yoshida S, Tanaka S, Kunihiro K et al. Diagnostic ability of highfrequency ultrasound probe sonography in staging early gastric cancer, especially for submucosal invasion. Abdom Imaging. 2005;30:518-523

22. Suzuki N, Yoshida M, Ohdaira $\mathrm{H}$ et al. Endoscopic submucosal dissection for the diagnosis and therapy of pedunculated gastric cancer with prolapse into the duodenal bulb: a case report. Int $J$ Surg Case Rep. 2018;43:49-55

23. Miyake M, Nishimura N, Shimodate $Y$ et al. Early gastric cancer with ball valve syndrome treated by endoscopic submucosal dissection. Clin J Gastroenterol. 2019;12:307-309

24. Sone Y, Honda T, Nakano S. Hyperplastic polyp causing ballvalve effect. Gastrointest Endosc. 2000;51:193

25. Sooklal S, Raja S, Jang S et al. Endoscopic submucosal dissection of a large pedunculated gastric polyp causing gastric outlet obstruction using clip-snare traction technique. VideoGIE. 2020;5:407-408

26. Cerwenka H, Bacher H, Mischinger HJ. Pyloric obstruction caused by prolapse of a hyperplastic gastric polyp. Hepatogastroenterology. 2002;49:958-960

27. Yriberry Urena S, Vila Guiterrez S, Salazar Muente F. Polypectomy and endoscopic management of a giant gastric polyp. Rev Gastroenterol Peru. 2010;30:167-171

28. Chen HW, Lu CH, Shun CT et al. Gastric outlet obstruction due to giant hyperplastic gastric polyps. J Formos Med Assoc. 2005;104:852-855
29. Dean PG, Davis PM, Nascimento AG et al. Hyperplastic gastric polyp causing progressive gastric outlet obstruction. Mayo Clin Proc. 1998;73:964-967

30. Aydin I, Ozer E, Rakici H et al. Antral hyperplastic polyp: a rare cause of gastric outlet obstruction. Int J Surg Case Rep. 2014;5:287-289

31. Burus IAS, Tata MD, Tak NAB. Gastric outlet obstruction secondary to a pedunculated hyperplastic polyp with early malignant changes. J Taibah Univ Med Sci. 2017;13:305-308

32. Lei WY, Chen MC, Hu CT et al. Progression of a prepyloric hyperplastic polyp. Gastrointest Endosc. 2008;68:570

33. Kumar A, Quick CR, Carr-Locke DL. Prolapsing gastric polyp, an unusual cause of gastric outlet obstruction: a review of the pathology and management of gastric polyps. Endoscopy. 1996;28:452-455

34. Pontone S, Pironi D, Eberspacher C et al. Endoscopic management of multiple large antral hyperplastic polyps causing gastric outlet obstruction. Ann Ital Chir. 2011;82:297-300

35. Kosai NR, Gendeh HS, Norfaezan AR et al. Prolapsing gastric polyp causing intermittent gastric outlet obstruction. Int Surg. 2015;100:1148-1152

36. Parikh M, Kelley B, Rendon G et al. Intermittent gastric outlet obstruction caused by a prolapsing antral gastric polyp. World $J$ Gastrointest Oncol. 2010;2:242-246

37. Sun CK, Yang KC, Liao CS. Endoscopic management of gastric polyp with outlet obstruction without polypectomy. Case Rep Gastroenterol. 2011;5:267-271

38. Gencosmanoglu R, Sen-Oran E, Kurtkaya-Yapicier O et al. Antral hyperplastic polyp causing intermittent gastric outlet obstruction: case report. BMC Gastroenterol. 2003;3:16

39. Freeman HJ. Endoscopic excision of a prolapsing malignant polyp which caused intermittent gastric outlet obstruction. World J Gastroenterol. 2005;11:5245-5247

40. Gashi Z, Polloshka AF, Veliu A et al. Endoscopic removal of a giant complicated hyperplastic gastric polyp. Open Access Maced J Med Sci. 2017;5:1047-1048

41. De La Cruz RA, Albillos JC, Oliver JM et al. Prolapsed hyperplastic gastric polyp causing pancreatitis: case report. Abdom Imaging. 2001;26:584-586

42. Jetha $\mathrm{Z}$, Lisi M. Prolapsed fundic gastric polyp causing gastroduodenal intussusception and acute pancreatitis. J Surg Case Rep. 2018;2018:139

Publisher's Note Springer Nature remains neutral with regard to jurisdictional claims in published maps and institutional affiliations. 